\title{
Challenges of Teaching English Communication to Arabic Students
}

\author{
Ehsan Mohammed Abdelgadir ${ }^{1}$ \\ ${ }^{1}$ Majmaah University, KSA \\ Correspondence: Ehsan Mohammed Abdelgadir, Majmaah University, KSA.
}

Received: December 26, 2018

Accepted: March 24, 2019 Online Published: March 27, 2019

doi: $10.5539 /$ elt.v12n4p179

URL: https://doi.org/10.5539/elt.v12n4p179

\begin{abstract}
The present study carries out to investigate and identify the communication problems that affecting the Teaching / Learning process of ELT. It aims to help teachers and learners to know the cause of these problems and to use and practice (IPA) in English pronunciation. It also sheds light on the most common mistakes of English sounds in relation to their spellings. That the teacher's knowledge of these errors makes him /her, able to avoid them. The researcher investigates the topic title: Challenges of teaching communication to Arab students. As a type of problems affecting the Teaching/Learning process of ELT. She follows an experimental design method to achieve this purpose. The subjects for the study were undergraduate students from University of Majmaah (Hotat Sudair College of Science and Humanities for girls). With the sample of two groups of fifty students of the same sex, standard, number, and degree of education. A case study in Hotat Sudair College for girls, to collect data from the subjects by observation through an oral test and statistical analysis. The study arrives at the following results: Only $13 \%$ of students care for segmental phonemes. Only $21 \%$ of students care for the correct pronunciation of words. Few learners use dictionaries to check English words' sound in their daily presentations. On the other hand, care for transcriptions of sounds when speaking. Many students lack the basics that are supposed to be learned for acceptable pronunciation then mispronounce words. Therefore, the researcher suggests some steps. She also finds new ideas for further investigations to improve the teaching/learning process and to achieve the aims of English communication.
\end{abstract}

Keywords: language use, communication competence, teaching / learning process

\section{Introduction}

Language studies constitute a very important field of knowledge because no person can live a normal life without language.It is a sign of the honor that Allah has given to human beings and by language, humans become different from other creatures. Motivating learners and helping them feel a real sense of progress is not an easy task. Thus, the process of communicative English suggests that teachers can actually help learners improve their English language abilities and encourage them. In addition to more process and methods of vocabulary and skills' improvements inside and outside classrooms. Teachers have to create simple dialogue's program to start with English (Activities, societies, English clubs, English volunteer practice outside in societies, theatre activities, role-plays, training sessions or workshops etc.). Although the teacher is the backbone of the teaching-learning process, but too busy to add any extra work in his/her office hours. In addition to the economic situations that affected even the textbooks and the teaching environment. This paper tries to present some methods that might help undergraduate students whose mother tongue is Arabic to communicate freely.

\subsection{Statement of the Problem}

Students use their native language during groups or pair-work. Practicing of English speech during lectures is normally very short, without enough time for the whole class to practice communications. In addition to that, most of the undergraduate learners lack the sufficient vocabulary, which leads to poor English communication with each other. They do not feel confident to make presentations. They normally exchange their English courses to Arabic for understanding. They ignore the system of using the phonetic symbols (IPA) for checking the correct pronunciation of English words. Therefore, they communicate their L1 more than L2, which leads to very poor communication. It becomes a challenge. Therefore, beginner learners need much knowledge of the linguistic forms, meaning, and function. They have to know that different forms of language perform a function. The author has mentioned some practices that she used while teaching English language pronunciation. It means that other problems appear between English sounds and spellings or the way of written and spoken English. There 
are twenty-five Arabic consonant sounds in number are used in everyday socialization different from of English. Thus, the main problems appear during the contrastive study of phonemic sounds between English and Arabic. In particular, the areas where English also differs than learners' language.

In addition to that, the effect of graduate teachers' role in the teaching/ learning process of ELT.

It concentrates on the difficulties that Learners and beginners face in using sounds and practicing them in communication.

\subsection{Significance of the Study}

The present study will be of great value to those who belong to the field of language learning. On the other hand, the lack of teachers' training, results in the lack of using guard methods, interactive programs of sounds' practice or updated dictionaries to check pronunciation. It makes EFL teachers aware of the contrastive areas of the English language itself. In addition to the sound systems of both languages (L1 and L2). Particularly the areas of common mistakes (problematic areas). It also helps learners to master all the significant sound features and basic structural patterns to communicate fluently.

\subsection{Objectives of the Study}

The objectives of this study are to:

1) Make analysis between (L1 and L2), to know the cause of these Problems.

2) Raise the teachers 'awareness as well as learners for mastering the sound patterns of English.

3) Encourage EFL learners to develop efficient language sounds.

4) Know the importance of grammar rules, vocabulary, spellings, and pronunciation. The aim of the present study is to find out some techniques that can help students to overcome these difficulties.

\subsection{Questions of the Study}

This study is expected to give answers to the following questions:

What are the communication problems that affect the teaching/learning process? This broad question can be divided into some specific questions.

1). To what extent does the teacher's role in teaching communication affect the learning process?

2) What are the areas of common mistakes?

3). Which consonant and vowel phonemes cause problems?

4). What are the words' sound problems in relation to their spelling?

5). What possible solutions can be suggested to overcome these problems?

\subsection{Hypotheses}

It is hypothesized that

1) Arabic EFL learners lack the basic knowledge of English sounds; confuse new sounds when dealing with the different areas in both languages (L1and L2); what makes it difficult to achieve better pronunciation and fluent communication. Then this study expects that:

2) Arabic EFL learners have common mistakes in the areas of (consonants and clusters).

3) Arabic EFL learners have common mistakes in the areas of (vowels and diphehongs)

4) Arabic EFL learners lack the basic knowledge of English speech, and then fail to achieve better communications (produce incorrect sounds).

5) Many teachers of English do not consider pronunciation as a relevant part of their education and training.

\subsection{Limits of the Study}

This study limits to the problematic areas of communication in teaching / learning English language in general, and contrastive areas for both languages in particular. It deals with the areas of sound systems (segmental phonemes features), that affects the teaching /learning process. It concentrates on the students of Majmaah University Hotat Sudair College for "girls". It reflects graduate teachers' need for training and refreshing courses. That is in order to find out suggestions for a better solution and recommendations for development. This study limits to the problematic areas of communication in teaching / learning English language in general, and contrastive areas for both languages in particular. It deals with the areas of sound systems (segmental and 
supra-segmental features), that affects the teaching /learning process. It concentrates on the students Hotat Sudair College of Science and Humanities for "girls". It reflects graduate teachers' need for training and refreshing courses and methods. That is in order to find out suggestions for a better solution and recommendations for the development.

\section{Literature Review}

Smith Bernard (1987) stated out that no Arabic verb is similar to (am, is, are).So, there must be much work on the areas of difficulties. Caswell (2006) pointed out that: "Creative problem solving is a powerful teaching method in the classroom that foster student engagement and motivation to learn".An also outside the classrooms. Delialioglu (2011) attempted that "An activity such as observation, guided inquiry, socialization, and interaction enhance students' encouragement.That there are many dialogues and conversation concern real environments. Shea and Bdjerano (2011) noted the group setting supports knowledge through social interactions. From the researcher's own point of view of teaching KSA undergraduate learners. Under a real environment of teaching (classrooms), being a supervisor in the field of experience, published a scientific paper and a textbook for the same domain. In order to spot out the difficulties and therefore to find a solution. Based on the findings of our paper entitled Challenges of Teaching English to Arabic Students (2016) concluded factors such as inter-language and mother tongue influence are the principal causes of the differences and difficulties. We have mentioned some practices that students have practiced while learning the English language to benefit the students to overcome the problems in pronunciation. More attention was paid to the areas of speech production and reception to show how language works. Nevertheless, the systems of the contact languages themselves have sometimes been contrasted and an important outcome of contrastive studies. Therein, sounds analyze into their different types and forms (English and Arabic). Thus, possible to trace the areas of difficulty and to investigate and identify communication problems that Arab learners face when learning (L2). Moreover, this part also surveys the outcome of some of the new contrastive. Tables and Charts design by the researcher is presented to summarize the different types of English spellings and pronunciation. In addition to symbol charts and tables, contain the contrastive sounds in both languages (L1, L2) as the basis of these problems. Therefore, to clarify the areas of contrast and to direct the English language teachers 'attention to better solutions. However, the researcher tries to make a contrast between (L1 and L2) sounds.

\subsection{Background}

This part sheds light on a framework of the sound systems and communication problems. The researcher designs tables for each sound's spellings and transcriptions, with the main purpose to clarify the areas of difficulties. All learners make mistakes, which are not only confined, to language learners, many who make mistakes of speech even in their native language.In case; there must be effort for better solution. Halliday (2003) states some evidence that clarifies that the second language differs not only in amount but also in types of interference. That is to focus not just on the positive properties of sounds but also their differences. As $/ \mathrm{j} /$ does not represent the first sound in just but the first sound in yes /jes/.

\subsection{Segmental Phonemes}

Chomsky (1999) explains that consonants and vowels are called segmental phonemes or segments. They are roughly referred to "what we say" which concerns the fundamental building blocks of sound structures. Sadock (2004) defines the phoneme as a unit such as in (sun, pun) differ in their initial consonantal phonemes /s/, /p/. Word pairs of this kind are known as Minimal pairs. The words "bill and pill "have different phonemic articulation areas of (b) and (p), which are also different in their meanings. Then minimal pairs are effective; particularly in showing how a phoneme contrasts with other causes differences in meaning. The pronunciation of a phoneme in different ways depends on its environment.

\subsection{Pronunciation Problems and the present Contrastive Studies}

Cook (2008) points out that, those learners of a second language differ from children acquiring their mother tongue in a number of ways. Then his point stands evidence that both languages are different in their acquisition. James (1980). Explains the pronunciation errors of three broad types; Segmental, Combinatorial, and Supra segmental. In Error analysis, he also identifies the problems with segmental consonant for example ,the interdental fricatives $[ð, \theta]$ that becomes [t] Thomas /toməs/, while / $\theta$ / in thousand / $\theta$ auzænd/ have the same spelling letters or the two initial letters $<$ th $>$ come to represent only one sound. Then the problems of the letter $\mathrm{r}_{\mathrm{s}}>$ at the plural ends ( $\mathrm{s}$ ) as in (dogs) changes to / $\mathrm{z} /$ in /dogz/, and stays /s/ in books/buks/. There are some differences between American and British pronunciation in certain areas. For example $/ \mathrm{r} /$ is pronounced in American English word bar/ba:r/ whereas in British /ba:/, but both are agreed in the length of the vowel/a:/. In British English the sound / $\mathrm{r} /$ will be heard if $/ \mathrm{r} /$ is followed by a vowel, for example, four eggs /f $\supset: \mathrm{r}$ e $\mathrm{g} \mathrm{z}$ /. 
Whereas in the area of supra segmental phonemes, stress and intonation are very different from segmental phonemes. For example, the English word 'pin' starts with aspirated ' $p$ ' which is stronger than unaspirated $/ p /$ in final position as in /mæp/ and unreleased /p/ after /s/ as in spoke /spəuk/ or before vowel in words' initials such as orange, umbrella or ink and eye.

In addition to words which have the same sound and different in their meanings for example,/rait/ refers to $<$ right $>$ which mean correct or not wrong or $<$ right $>$ the opposite of left and $<$ write $>$ (using of a hand or pen). This effect is stronger for Arabic beginner learners. Contributing to fluency in English is the systematic use of reducing or weak forms English. The sound $\mathrm{ch} / \mathrm{t} / \mathrm{f}$ in chair $/ \mathrm{t} / \mathrm{e} /$, for example, is the joining of sounds $/ \mathrm{t} / \mathrm{and} / \mathrm{J} /$ has a different pronunciation in words' final position as in catch $/ \mathrm{kæt} f /$ or which, /wit $\int$. There is many spoken English on films, tapes, gramophone records and on the radio with different accents. Thus, educational theories in classrooms are very important. For example in the initial consonant /t/ in true /tru:/ the lips are made round but not flat shape as in tea /ti:/ or open in task /ta:sk/. Contrastive vowel sounds: [/ つ:/, /æ/,/ð/,/o/] aren't phonemic in Arabic. Arabic /aa/ ranges from [a:] to [u:] and /a/ ranges from [æ] to [ə]. In addition to that, most of Arabic dialects contain /ee/ instead of [(ii), (ee)] or [(oo) for]. All English vowels are voiced. That is to say, there is no point of articulation. Then teachers have to provide learners with the new language rules in patterns of contrast and to let learners practice these patterns intensively through drills until they internalize these rules as habits. These ways might reduce mother-tongue interference and language transfer. The problematic areas of different sounds become clear by more drilling practice in both listening and speaking .e.g. (Say the odd sound etc.) Alternatively (Put each word in the right column of sounds). Furthermore, there is no difference between print and handwriting in Arabic. There is no capitalization in Arabic. Teachers' knowledge of these contrastive areas is very important. Thus, to find a better way for a solution.

Table 1. Contrastive English and Arabic vowels

\begin{tabular}{|c|c|c|c|c|c|c|}
\hline \multicolumn{4}{|c|}{ English vowels } & \multicolumn{3}{|c|}{ Arabic vowels } \\
\hline & Front & Central & Back & & Front & Back \\
\hline \multirow[t]{2}{*}{ High } & /i:/ & & /u:/ & High & /ii/ & /uu/ \\
\hline & /i/ & & $/ \mathrm{u} /$ & & /i/ & $/ \mathrm{u} /$ \\
\hline \multirow[t]{2}{*}{ Mid } & /e/ & /ə:/ & /כ:/ & & & \\
\hline & & $10 /$ & /o/ & & & \\
\hline \multirow[t]{2}{*}{ Low } & $/ \mathfrak{m} /$ & IN & & Low & & $/ \mathrm{a} /$ \\
\hline & & & /a:/ & & & /aa/ \\
\hline
\end{tabular}

\subsubsection{Arabic vowels}

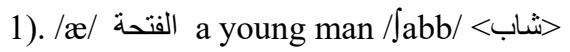



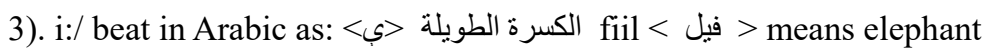

4). /e/ as in bet and it is not found in Arabic.

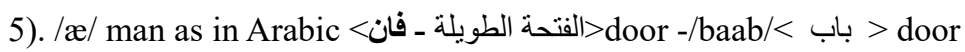

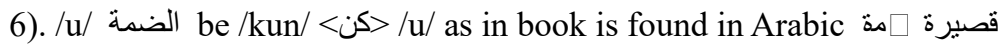

7). /u: / / /uu/ whale /huut/ من طويله > حوت >

8). / / / as in about, it does not exist in Arabic

9). Long vowel / :/ doesn’t exist in Arabic and short /o/

10). /aw/ means 'if 'It is pronounced as /law $/<$ ل ل $>$

11). /ay/ means 'in order to' and pronounced as $>>$

/ii /- high front close unrounded vowel /i/-high front open vowel. /a/-mid front unrounded vowel. Arabic writing starts from right to left and without capitalization. Most of the letters in Arabic are cursive (connected) (؟ متصلة (؟) (ع.) Noticeably, the schwa vowel occurs in Arabic especially in unstressed syllables in the first syllable in the name / 'Mubarak/ or /'Mohammed/. Which is the cause of FL learners' problems with schwa vowel, 
because in English it represents by many different letters for example <ous $>$ in gracious/grei $\int a s /$ or thorough $/ \theta \wedge$ rə $/ .<\mathrm{a}>$ about/ə’baut/ $-<$ or $>$ forget/fə'get/ $<\mathrm{u}>$ Autumn/ $\supset$ :təm/etc. These different vowel letters in contrast to Arabic orthographic conventions stand evident for FL learners' confusion, substitution or replacement.

\subsubsection{Arabic Consonants}

\subsubsection{Arabic Stops}

Consonant $/ \mathrm{p} /$ does not exist in Arabic. So Arabic speaking students confuse it and replace it with $/ \mathrm{b} /-/ \mathrm{p} /$ is a separate phoneme from $/ \mathrm{b} /$ that is a voiced bilabial stop. They say $<$ bray $>$ for pray and $<$ beoble $>$ for people. Arabic $\langle ب>(ب)$ (بدأ - عبق - طب) is voiced bilabial stop. /t/ a voiceless dental stop $<ت$. The difference is in the point of articulation, which is alveolar in English rather than dental in Arabic. /t ط طلب- > boiceless velarized stop >يطلب - مسك > It does not exist in English. It is similar to an allophone in < tall - stop - but $>$ as an area of common mistakes. ./d/ $/<>>$ voiced dental stop. The difference between Arabic and English is in the point of articulation,

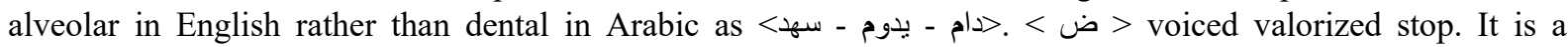

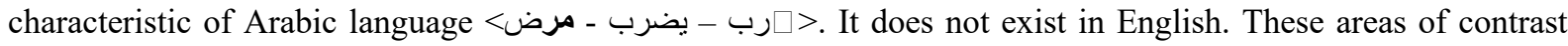
between (LI, and L2), make the differences clear. Even in their native language, students have some areas of confusion.Therefore; teachers have to direct an open ear for listening to their students' pronunciation or replacement. Moreover, to add much effort especially for the groups of lower performance. Extra homework concerns the areas of difficulties). Leads them to share in simple activities for participation inside or outside the classrooms. Graduate teachers have to be attention to the pronunciation of these grammatical rules in relation to their sounds.

Table 2. Contrastive English and Contrastive Arabic stops

\begin{tabular}{|c|c|c|c|}
\hline Stops & Arabic & IPA & English \\
\hline \multirow[t]{10}{*}{ Voiceless } & - & $/ \mathrm{p} /$ & $<\mathrm{p}>$ \\
\hline & $<>>$ & $/ \mathrm{t} /$ & $<\mathrm{t}>$ \\
\hline & $\langle b\rangle$ & $/ \mathrm{t} / /$ & - \\
\hline & $<$ | > > & $/ \mathrm{k} /$ & / k / \\
\hline & >ق > > & $/ \mathrm{q} /$ & - \\
\hline & >ــ الهمزة > & /?/ & - \\
\hline & < ب & $/ \mathrm{b} /$ & $<\mathrm{b}>$ \\
\hline & > ض> & / d / & - \\
\hline & $<د>$ & $/ \mathrm{d} /$ & $<\mathrm{d}>$ \\
\hline & >> & $/ g /$ & $<\mathrm{g}>$ \\
\hline
\end{tabular}

$/ \mathrm{k} /\langle 4\rangle$ voiceless velar stop. It appears at the beginning of stressed syllables and released in word -final position

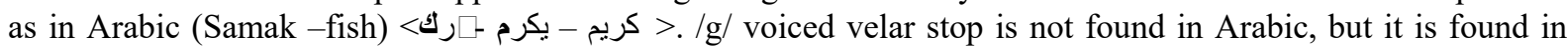

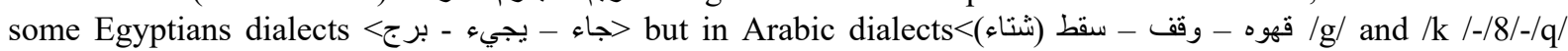

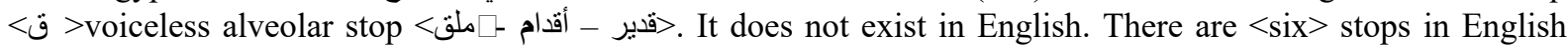
whereas $<$ nine $>$ stops in English. These dashes in the table above to show the sounds that are not found in both languages (L1 and L2).

\subsubsection{Arabic Affricates}

1. / $\mathrm{t} /$ /voiceless Plato alveolar does not occur in Arabic, but in some Sudanese dialects used to express admiration or in some juncture of $/ \mathrm{t} /$ and $/ \int / .2$. $/ \mathrm{X} /\langle\mathrm{r}\rangle$ voiced Plato alveolar affricate is found in some parts of the Arabs world Saudis, Iraqis, Syrian and it is found in initial and middle position جميل, يجلس, درج) Contrastive areas of Arabic and English Affricates: There is only one Affricate in Arabic while two in English. 
Table 3. Contrastive areas of Arabic and English Affricates

\begin{tabular}{llll}
\hline Affricates & Arabic & IPA & English \\
\hline Voiceless & - & $/ \mathrm{t} / /$ & $<\mathrm{ch}>$ \\
Voiced & $<\mathrm{r}>$ & $/ \mathrm{db} /$ & $<\mathrm{j}>$ \\
\hline
\end{tabular}

\subsubsection{Fricatives}

In English there are nine fricative sounds $/ \mathrm{f} /, / \mathrm{v} /, / \theta /, / \mathrm{\partial} /, / \mathrm{s} /, / \mathrm{z} /, / \mathrm{J} /, / \mathrm{z} /, / \mathrm{h} /$ while in Arabic there are fourteen

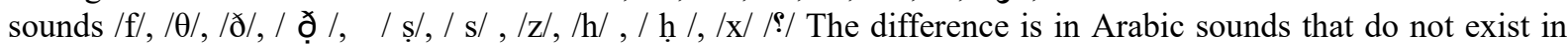

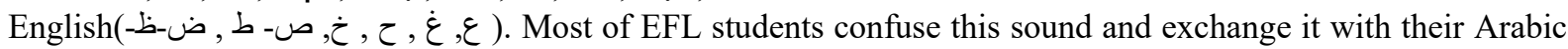
one $/ \mathrm{f} /$. That led them to produce non-English sounds and make errors. Such as (ferry - for very) or (fillage for village).

Table 4. Fricatives

\begin{tabular}{|c|c|c|c|}
\hline \multicolumn{4}{|l|}{ Fricatives } \\
\hline & Arabic & IPA & English \\
\hline \multirow[t]{8}{*}{ Voiceless } & < $>$ & $/ \mathrm{f} /$ & $<\mathrm{f}>$ \\
\hline & $<\doteq>$ & $/ \theta /$ & $<$ th $>$ \\
\hline & > & $/ \mathrm{s} /$ & $<\mathrm{s}>$ \\
\hline & > ص > & /ș / & - \\
\hline & > ش > > & $/ \mathrm{d} /$ & $<\mathrm{sh}>$ \\
\hline & $<\dot{\tau}>$ & $/ \mathrm{x} /$ & $->$ \\
\hline & > هاء > & $/ \mathrm{h} /$ & $<\mathrm{h}>$ \\
\hline & $<\tau>$ & / ḥ / & $->$ \\
\hline \multicolumn{4}{|l|}{ Voiced } \\
\hline & $<->$ & $/ \mathrm{v} /$ & $<\mathrm{v}>$ \\
\hline & $<\dot{j}>$ & /ð/ & $<$ th $>$ \\
\hline & $<\dot{b}>$ & / // ðִ & - \\
\hline & $<j>$ & $|\mathrm{z}|$ & $<\mathrm{z}>$ \\
\hline & > > & $/ 3 /$ & $<\mathrm{j}>$ \\
\hline & $<\dot{\varepsilon}>$ & 181 & - \\
\hline & $<\varepsilon>$ & $/ ? /$ & - \\
\hline
\end{tabular}

The knowledge of these contrastive areas help teachers to adopt the best methods that lead to best results to direct time and effort towards these problematic areas. That is to say, using effective teaching. The knowledge of EFL sounds and how they are differ from the learners' native language sounds; and what problems are caused by these differences between both sound systems $/ \theta /\langle\dot{\Delta}\rangle$ is a voiceless interdentally fricative Some difficulty

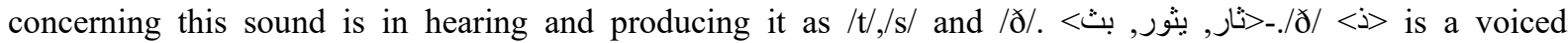
interdentally fricative difficulty concerning this sound is hearing and producing it as $/ \mathrm{d} /, / \mathrm{z} /, / \theta /$ or $/ \mathrm{d} /$ as gold

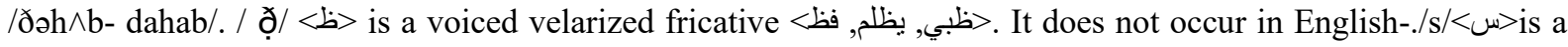

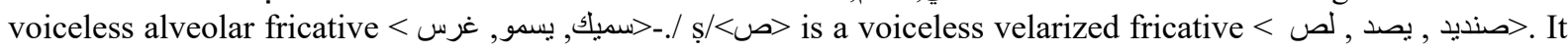
does not occur in English. The above Table 4 compares Arabic sounds that do not exist in English. They cause difficulty for Arab students, who always substitute them.

\subsubsection{Arabic Trill or Flap}

A trill or flap sound is found in Arabic. There is only flap in Arabic whereas in English it is a semivowel or a retroflex. Trill or flap sound /r/ exists in Arabic. It is a semivowel sound in English /r/ is voiced alveolar flap. هاء, > Arabic/r/ does not exist in English. The confusion occurs because in Arabic, it represents by 
/ doesn’t occur in English، learners tend to substitute it as in

Table 5. Arabic and English: Contrastive areas of $/ \mathrm{r} /$

\begin{tabular}{lllc}
\hline Trill and flap & & & \\
\hline & Arabic & IPA & English \\
Voiced & $<\lrcorner>$ & $/ \mathrm{r} /$ & - \\
\hline
\end{tabular}

\subsubsection{Nasals}

In Arabic, there are only two nasals /m/,/n/ - 1./m/<>is a voiced bilabial nasal. > > مجيد, يمجد, علم $>2$. $/ \mathrm{n} /<>$ is a voiced alveolar nasal. When $/ \mathrm{n} /$ is followed by $/ \mathrm{t} /$, most of the $/ \mathrm{n} /$ swallowed into. $/ \mathrm{t} /$ is dominant. For example, the air changes from nose >بنت >to mouth and this is the reason for explosion>نصر, ينصر, لبن/M/ is not found in English, but it can be found in some Sudanese dialects for example in a word stand for food by children $/ \mathrm{D} /$. It forms a difficulty for Arab students in hearing or producing (ng / $/$ / or even (n k).

Table 6. Arabic and English contrastive Nasal sounds

\begin{tabular}{llll}
\hline Nasals & & & \\
\hline \multirow{3}{*}{ Arabic } & E $/$ IPA & English \\
& $<\rho>$ & $/ \mathrm{m} /$ & $<\mathrm{m}>$ \\
& $<\dot{0}>$ & $/ \mathrm{n} /$ & $<\mathrm{n}>$ \\
& $<->$ & $/ \mathrm{D} /$ & $<\mathrm{ng}>$ \\
\hline
\end{tabular}

Table 7. Arabic and English contrastive areas of Lateral sounds

\begin{tabular}{llll}
\hline Laterals & Arabic & IPA & English \\
\hline & $<J>$ & $/ 1 /$ & $<1>$ \\
& $<J>$ & $/ 1 /$ & $<->$ \\
\hline
\end{tabular}

\subsubsection{Laterals}

In English there is only lateral whereas two laterals sounds in Arabic $/ 1 />$ ليل, حلح, > is a voiced alveolar lateral

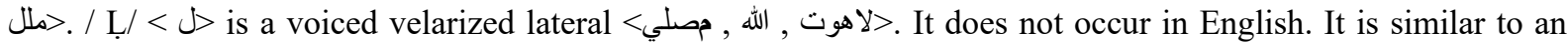

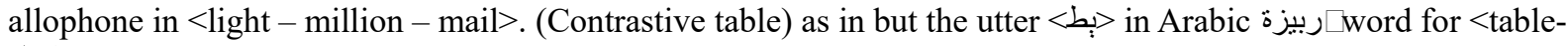
طاولة > ب > > and I do not know. That is to say that, /d/ is voiced whereas /t/ is voiceless as $/ \mathrm{p} /$ and $/ \mathrm{b} /$ so, there are differences, very similar to those that exist in English. The main differences are in the aspiration of $/ \mathrm{t} /$ in the degree of voicing of $/ \mathrm{d} /$. Arabic language has no aspirated consonants. Therefore, English /d/ is like English /p/ and there are two types of Arabic /t/ or /d/ $/>$ ض, د, b

Table 8. Arabic and English contrastive semivowels

\begin{tabular}{llll}
\hline Semivowels & & & \\
\hline \multirow{2}{*}{ Arabiced } & Arabic & IPA & English \\
& $<\rho>$ & $/ \mathrm{w} /$ & $<\mathrm{w}>$ \\
& $<->$ & $/ \mathrm{r} /$ & $<\mathrm{r}>$ \\
& $<\mathrm{s}>$ & $/ \mathrm{j} /$ & $/ \mathrm{y} /$ \\
\hline
\end{tabular}

\subsubsection{Semi Vowels}

There are three semi-vowel sounds. They are $/ \mathrm{w} /, / \mathrm{r} /, \mathrm{j} /$ that are changed to a vowel in final positions. In Arabic,

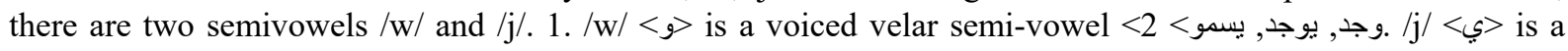


voiced palate-alveolar semi-vowel بلهو, أمين, يجري> The chief problems come out of contrasting patterns of these sounds in both languages Arabic and English, which cause difficulties in learning L2. Thus, Sudanese learners fail to distinguish between $/ \mathrm{p} /$ and $/ \mathrm{b} /$ or $/ \mathrm{f} /$ and $/ \mathrm{v} /$ or/ $\mathrm{D} /$ which does not occur at all in Arabic. English contains twenty - four consonant sounds while Arabic contains thirty-one consonant sound.Therefore, Arabic is a consonantal language.

\subsubsection{Arabic Consonant Clusters}

The range of consonant clusters that occur in English is much wider than in Arabic. It does not have double initial clusters as (cc), whereas in English occurs initial, medial or in final position. Furthermore, they cause serious problems for Arab learners.

\section{Methodology}

\subsection{Overview}

The teacher's knowledge of these contrastive areas of sounds in both languages enables him/ her to pinpoint the problematic areas and to predict the problems before they happen. Therefore, to pay more attention to each step and plays the needed role for improving students' standard this chapter includes two parts. It contains information about the identification of the participants who use in this study. In addition to their population and setting. A t-test designs to validate and evaluate the data collection instrument. The second part of this chapter clarifies the instruments of the study, which includes the steps for collecting data. It involves an oral test and the procedures followed. Essentially, the present study focuses on communication problems affecting the teaching/ learning of English language. A case study of Hotat Sudair college student's girls. The objectives of this research are, to identify and analyze the most common mistakes and the problematic areas of communication in relation to their spellings. Then to arise language teacher's awareness as far as learners to the English sounds. The main purpose is to point out the difficulties that FL learners and readers face in learning English communication. Furthermore, to find out suggestions and remedial solutions.

\subsection{Research Method}

This research designs an experimental method, which is suitable for comparing language learners' performance after a certain program and investigating the effect of individual differences on language acquisition. It involves the following steps: Collecting data from two groups of learners who have been selected randomly and assigned randomly (control group and experimental group) as a homogeneous equal sample to represent the population. Using a suitable sampling technique, a treatment, standardized test for data collection and statistical measurement (T-test) for validation. This part aims at investigating and identifying the problems of communication in ELT, which affect the teaching/learning process. Thus, to find out certain language teaching methods and materials that might achieve beginners 'need. First, the researcher provides an oral pre-test for both groups. While subjects read aloud, examiner observes the tested area of dialogues and sounds and assigns the score to each subject. That is for finding out if there is any individual differences between the two groups; in order to be used in the experiment as Experimental group and Control group. After testing the subjects with the pre-test, the researcher divides the general population that consists of a hundred student girls, into two groups of fifty per each to be used as (Experimental and Control group). Then the experimental group is given a certain practice under controlled conditions for the sake of examining its effects on them. After treating research subject with the treatment, a posttest is prepared to measure the effects of the treatment on them (using the same pre-test). Therefore, tests before and after the treatment are designed. Therein a (T-test) is used for comparing the means of both groups in order to find out whether there is a real difference between them. The researcher plans a type of questions concerning the study focus (see appendix). That is for finding out possible remedial solutions, suggestions and recommendations

\subsection{Test}

This study sets out to identify the communication problems that learners face in learning English. Thus, the content limits to assess the areas that cause problems That is to say the areas of dialogues and sound systems in relation to their alphabetical letters. A test designs according to a specific purpose and a limited time and objectives. This step follows by the selection of the procedure to be adopted in the source of data collection. For this purpose, the researcher selects testing as a data collection technique which suites the study requirements. Upon the completion of data gathering phase, the data analysis stage will start; therein data is analyzed quantitatively using frequency counts and percentages. The purpose of the oral test is to measure subjects' language fluency and accuracy before and after being involved in the experience. This test consists of three parts. They concentrate on the subject matter of communication. The total marks for this test are (60 marks), twenty 
scores for each test. Time allocated for the whole test is (three hours), under a controlled condition. 1. The first oral test deals spellings. Subjects are taken individually. While the subjects read aloud, the meanly with vowels diphthongs in relation to their researcher observes the tested areas of sounds and assign scores to each subject. Each error done by the student was reducing her score.

\subsubsection{The First Test on: Vowels}

(1./i: /, 2. /i/, 3. /e/, 4. /æ/, 5. /ə:/ , 6./ə/, 7.// 8./a:/, 9./o/, 10 ./د:/, 11./u, 12 /u:/ and eight diphthongs (1. /ei/, 2. /ai/, 3. / $\mathrm{Ji} /$, 4. /iə/, 5. /au/, 6. /uə/, 7. /əu/ 8. /eə/. There are twenty items, one mark for each (20 marks) as in the table below.

Table 9. First test examples

\begin{tabular}{lllll}
\hline 1. beat & 2. pin & 3. pen & 4. pan & 5. early \\
\hline 6. brother & 7. some & 8. heart & 9. watch & 10. bought \\
11- could & 12. spoon & 13.gay & 14. bite & 15 joy \\
16. clear & 17.noun & 18.pure & 19. no & 20. there \\
\hline
\end{tabular}

The spelling areas (beat, bet, bat, bite boat, bought, but, put)

\subsubsection{The Second Test}

It deals with the problematic areas in consonants + clusters $(20$ items $=+(20$ marks $)(\mathrm{p}, \mathrm{v}, \theta, \mathrm{g}, \mathrm{\jmath}, \mathrm{d}, \mathrm{g}, \mathrm{f}, \mathrm{f}),(\mathrm{st}, \mathrm{sk}$, $\mathrm{kl}$, sp, sn,pl, tr , nst , str , nstr ,rld, kst).

Table 10. Second test examples

\begin{tabular}{lllll}
\hline 1. pig & 2. five & 3. thin & 4.regret & 5. then \\
\hline 6. jump & 7. sing & 8. chin & 9. stop & 10 school \\
11- clear & 12. spoon & 13.snake & 14. plan & 15. try \\
16. constant & 17. distract & 18.costruction & 19. world & 20.context \\
\hline
\end{tabular}

\subsubsection{The Third Test}

It contains communication dialogues More Example American English Conversations. After carrying out the pre -test for finding out any individual differences, then both groups expose to the experiment as experimental and control. Thus far, both of them are given the three tests respectively. All students of both experimental and control groups are tested in the same manner individually. The researcher tests the students' receptive ability by giving her a chance to read aloud the following words. Each error done by the student reduces her score. Therefore, students' evaluation depend on these three tests, according to their oral readings. Therein scores are distributed as follow. After correcting the student's oral answers by the researcher herself. Then marks are being put in special tables for the statistical treatment.

\subsubsection{The Setting Place and Time}

This test implements Hotat Sudair college of Science and Humanities for girls during (20 November/ 2018).

\subsubsection{Test-validity}

Data collection started by submitting the test to the respondents. It is limited to assess the areas of communication and sound systems, which cause problems for FL learners. It consists of three parts. Time allocated for the whole test was three hours. All students of both experimental and control groups were tested individually.

1. for the result of the first test in the areas of (vowels and diphthongs). From this table the results of the first test for the experimental group can be calculated into percentages, using the average mark (the mean), the standard deviation and the normal deviation as follows: 
Table 11. Eperimental group result for $1^{\text {st }}$ test

\begin{tabular}{cc}
\hline Mark & Fragment \\
\hline 11 & 1 \\
10 & 5 \\
9 & 6 \\
8 & 6 \\
7 & 6 \\
6 & 14 \\
5 & 6 \\
4 & 4 \\
3 & 2 \\
\hline
\end{tabular}

$\grave{X}=11+50+54+48+42+84+30+16+6=3413 \div 50=6.82$

$\mathrm{SD}=1.996$

$6=1.976$

These results reflect the experimental group's low achievement .They illustrate and clarify the experimental group's scores before having the treatment. In order to make sure of this, the same procedure is used with the control group. By adopting the same procedure with the second group to calculate the mean (X) , the standard deviation (S) and the normal deviation as follow: Table 12 Control group for first test 2 . For the result of the first test, that includes vowelsand diphthongs. By using the same procedures, the average mark(the mean), the standard deviation and the normal deviation, for the same test in the control group as follow:- $\dot{X}$ $=12+11+50+80+35+72+30+20=355 \div 50=7.1$

$\mathrm{SD}=2.002$

$6=1.982$

Table 12. The result of the control group (2)

\begin{tabular}{ll}
\hline Mark & Fragment \\
\hline 13 & 1 \\
11 & 1 \\
10 & 5 \\
9 & 5 \\
8 & 10 \\
7 & 5 \\
6 & 12 \\
5 & 6 \\
4 & 5 \\
\hline
\end{tabular}

These results show the informants' lower performance before the treatment in vowels. Then, by comparing the performance of the two groups (Experimental and control), it is noticed that:

a. The mean for the control is greater than the mean for the Experimental group $(7.1>6.82)$ with the difference of $(7.1-6.82=0.28)$. Therefore, in order to find out if there is any difference between them or not, the following formula of the $\mathrm{t}$-value is used as follows:

$\mathrm{t}=(\dot{\mathrm{X}} 1-\dot{\mathrm{X}} 2) / \sqrt{ }^{-}\left(\mathrm{S}^{2}+\mathrm{S} 2^{2}\right)(\mathrm{N}-1)$ 
Table 13. T- Test

\begin{tabular}{lllll}
\hline & $\mathrm{N}$ & $\mathrm{X}$ & $\mathrm{S}$ & 6 \\
\hline The Experimental group & 50 & 6.82 & 1.996 & 1.076 \\
The Control group & 50 & 7.1 & 2.002 & 1.982 \\
\hline
\end{tabular}

$\mathrm{t}=(6.82-7.1) / \sqrt{ }^{-}\left(1.996^{2}+2.002\right)^{2} /(50-1)=0.69$

1. According to t-test table, it is found that the degree of freedom (d.f) is (98), for a probability of (95) under the (d.f) $98 \mathrm{so}$, the $\mathrm{t}$ - value is 1.658 whereas our value is less than the wanted value.

4. For the first test, the two groups are similar.

5. As a result, there is no statistical differences between the two scores of the two groups in general. The difference that occurs due to special effect or certain treatment.

6. Moreover, our consideration to select the two groups as one to be experimental and the other control are right.

(2) For the result of the second test (consonants and clusters).

By using the table below to calculate the mean, the standard deviation and the normal value to reach to the following results as

Table 14. Experimental group for second test

\begin{tabular}{ll}
\hline Mark & Fragment \\
\hline 14 & 1 \\
12 & 2 \\
11 & 3 \\
10 & 8 \\
9 & 9 \\
8 & 12 \\
7 & 5 \\
6 & 6 \\
5 & 1 \\
4 & 3 \\
\hline
\end{tabular}

$\dot{X}=13+24+33+80+81+96+35+36+5+12=413 \div 50=8.32$

$\mathrm{SD}=2.103$

$6=2.082$

The experimental group is exposed to the treatment for a given period before posttest. After getting (post -listening) in the area of consonant and clusters before the test, then both groups had a posttest (using the same pre-test). As a result, these scores show the experimental group improvement due to practicing. Therefore using the same test to clarify the similarities and differences between both groups. For the results' of the second test in the areas of consonant and clusters

Table 15. Control group $2^{\text {nd }}$ test

\begin{tabular}{ll}
\hline Mark & Fragment \\
\hline 13 & 1 \\
12 & 1 \\
\hline
\end{tabular}




\begin{tabular}{ll}
\hline 11 & 3 \\
10 & 8 \\
9 & 6 \\
8 & 10 \\
7 & 3 \\
6 & 7 \\
5 & 5 \\
4 & 5 \\
3 & 1 \\
\hline
\end{tabular}

By using the above procedures, theX, $\mathrm{S}$ and the normal deviation from this table to find out the following results.

$\hat{X}==13+12+33+80+54+80+21+42+25+20+3+383 \div 50=7.66$

$\mathrm{SD}=2.395$

$6=2.371$

By comparing the performance of the two groups (experimental and control), it is found that:

1. The two groups are of the same number (50).

2. The mean mark for the experimental group (8.32) is greater than the mean mark for the control group. These effects due to the given practice under certain conditions, which the experimental group had had before the posttest. That is for the sake of examining the treatment's effect on the experimental group.

3. To make it sure, the t-test formula is used as:

Table 16. T-Test

\begin{tabular}{lllll}
\hline & $\mathrm{N}$ & $\dot{X}$ & $\mathrm{~S}$ & 6 \\
\hline The experimental group & 50 & 8.32 & 2.103 & 2.082 \\
The control group & 50 & 7.66 & 2.395 & 2.371 \\
\hline
\end{tabular}

$\mathrm{t}=(\dot{\mathrm{X}} 1-\dot{\mathrm{X}} 2) / \sqrt{ }^{-}\left(\mathrm{S} 1^{2}+\mathrm{S} 2^{2}\right)(\mathrm{N}-1)$

$\left.\mathrm{t}=\left(\dot{X}^{2}-\dot{X}^{2}\right) / \sqrt{ }^{-}\left(\mathrm{s} 1^{2}+\mathrm{s} 2^{2}\right) * \mathrm{~N}-1\right)=(8.32-7.65) / \sqrt{-}\left(2.103^{2}+2.395^{2}\right) 49=1.47$

Depending on the t-test table, it is found out that:

1. The value under the degree of freedom $98=1.289$ across the percentage $90 \%$. This makes it sure that, there is a statistical differences between the performance of the two groups in favor of the experimental group. Thus, the results show the improvement of the experimental group due to the treatment. $36 \%$ learners improve to better pronunciation.

Table 17. Experimental for the result of the third (testing communication skills)

\begin{tabular}{ll}
\hline Mark & Fragment \\
\hline 11 & 3 \\
10 & 4 \\
9 & 4 \\
8 & 8 \\
7 & 4 \\
6 & 10 \\
5 & 8 \\
\hline
\end{tabular}




\begin{tabular}{ll}
\hline 4 & 6 \\
3 & 3 \\
\hline
\end{tabular}

2. For the results of the second test in the areas of consonant and clusters, the performance of the control group was lower. From this point of view, it is found that, both groups are similar. They are differ due to certain experiments as shown by the $\mathrm{t}$ - distribution. $\dot{X}=33+40+36+64+28+60+40+24+9=334 \div 50=6.68$

$\mathrm{SD}=2.224$

$6=2.22$

For the results of the control group

Table 18. Using the same second test consonants and clusters

\begin{tabular}{ll}
\hline Mark & Fragment \\
\hline 10 & 4 \\
9 & 5 \\
8 & 8 \\
7 & 3 \\
6 & 14 \\
5 & 9 \\
4 & 7 \\
\hline
\end{tabular}

The mean $=40+45+64+21+83+45+28+327 \div 50=6.54$

$\mathrm{SD}=1.842$

$6=1.842$

Table 19. T- Test

\begin{tabular}{lllll}
\hline & $\mathrm{N}$ & $\dot{X}$ & $\mathrm{~S}$ & 6 \\
\hline The experimental group & 50 & 6.68 & 2.244 & 2.22 \\
The control group & 50 & 6.54 & 1.842 & 1.842 \\
\hline
\end{tabular}

This table shows that

The means of both groups are similar. In relation to the t-test, both groups are equal in number.

Then calculate the $\mathrm{t}$-value for validation as follow:

$\left.\left.\mathrm{T}=\left(\dot{X}_{1}-\dot{X}_{2}\right)\right) / \mathcal{N}^{-}\left(\mathrm{S}^{2}+\mathrm{S} 2^{2}\right)(\mathrm{N}-1)=(6.68-6.54)\right) / \mathcal{N}^{-}\left(2.244^{2}+1.842^{2}\right) 49=$ According to this equation, the $\mathrm{t}-$ value is 1.658 and 0.33 is more less than our value. That is to say, we are right to select one group as experimental and the other as control. In the light of these results, it is obvious that:

1). The percentage of the students who had failed the test is bigger than the ones who passed. Only $15 \%$ who pronounced correct vowel sounds.

2). When the two groups applied the same experiment or getting similar practice, the results are the same as the t-test results shown in the second test results. On the other hand, they differ according to the effect of the type of treatment.

\subsubsection{Observation}

Arabic students have problems of pronunciation caused by: 1) Lack of using dictionaries 2) Lack of student's interest 3) Lack of English communication practice. Lack of looking up into dictionaries: Many of the students did not use any dictionary to check sounds or spellings, with the cause of not having time to check. So, they are depending on the word's spelling when reading. To solve these problems we have to follow Jane Yates (2005) 
suggestions: "The spelling of the vowel sounds, in particular, is an unreliable guide to their pronunciation. In addition, many vowels and consonant letters are silent: they are simply not pronounced at all. Each sound is considered separately, by sound rather than by spelling, automatically, students will learn them by practicing symbols of sounds in all possible positions in a word spellings- Lack of English communication practice. Although a language teaching involves pronunciation, the use of the pronunciation system of a language is a matter of habit or a system of habits. Huang (2007) points out: "the fact that children learn the pronunciation of language around them without being taught that pronunciation." Each English sound has many different areas of spelling. Therefore, it is observed that many students who have missed lectures, depends on spellings to pronounce words. e.g./k/ sound because it occurs in Arabic language, it is easy for learners to produce, but it has different areas of spellings, such as $<\mathrm{k}>\mathrm{key},<\mathrm{x}>\operatorname{mix},<\mathrm{ch}>$ character, $<\mathrm{q}>$ queen, $<\mathrm{c}>>$ cat etc. The same letters have another sound such as $<\mathrm{ch}>$ in (school or schwa or chair ) or $<\mathrm{c}>$ circle are another areas of confusion. Taking into account that, consonants $/ \mathrm{p} /, / \mathrm{t} /, / 3 /, / \mathrm{y} /$ which are not found in Arabic. On the other hand, the

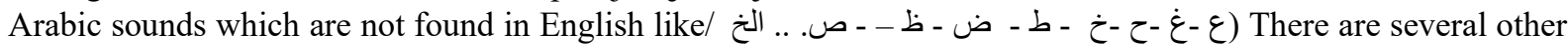
reasons for not differentiating the differences between the languages. Even the similar ones are different than English: for example, one Arabic letter is formed by two letters in English like (sh- the- ch -etc.). [The letter (ch/ in chair) which does not exist in Arabic has different pronunciation as $/ \mathrm{k} /$ in school and $/ \mathrm{f} /$ in the chair or $/ \mathrm{J} / \mathrm{in}$ machine etc.]. In addition, capital $(\mathrm{O})$ is used for Omer - Osama that have different initial letters in Arabic. The sound symbols association may be presented by means of picture-symbols. At first, just initial sounds are given attention but later, pupils may be asked to listen to and hear sounds in other positions within the words. Sounds of vowels and consonants may be taught first and then used to form words. Small words are formed by joining two simple sounds such as /i/ and /t/ to make the English /it/. Further, these sounds are expanded to include, additional sounds to form bigger words, for example $<$ sit $>$, sitting. Additionally, regular spelling for words are taught first followed by irregular ones, for example <light, world, listen $>$ etc. A language teacher can proceed from easy and little words too difficult and large ones and from the regular spelling of words to irregular ones to facilitate the teaching of reading by the Phonic(s) Method and the Knowledge of these contrastive areas as:

\section{Data Analysis and Discussion}

\section{Students' results for the first test}

\subsection{Vowels and Diphthongs Analysis}

These results stand evident that there is a quite difference between English and Arabic vowel. The reason for why most of EFL learners of have communication problems in the areas of segmental sounds (vowels, diphthongs). They pronounce sounds according to their spellings. For example $<0>$ in body - was- wall or $<\mathrm{a}>$ in heart- cart- far or $<\mathrm{u}>$ in spoon- soon- moon or schwa in possible- particular- forget. The results clarify that these learners produce incorrect pronunciation 1. From students' test in the area of vowels and diphthongs, the researcher reaches to the following points: a. $/ \mathrm{i} /$ and /e/ are normally confused so students produce $<$ bid for $>$ bed -will and well - till- tell- thin-then - b. $/ \mathrm{a} /$ and $/ \wedge /$ are also substituted by each other that learners utter but for bat- some- come - custom- tongue- thorough- exchanged to $<\mathrm{o}>\mathrm{c}$. /o/ and $/ \mathrm{J}: /$ are replaced by one another, students use /o/ for both sounds or mixed with $<\mathrm{u}>\operatorname{good}-\mathrm{God} \mathrm{d}$. /æ/ and /a:/ are also confused, students tend to replace them as $/ \mathrm{ka}: t /$ for $/ \mathrm{krt} /$ and $/ \mathrm{kæ} /$ for $/ \mathrm{ka}: /$. Alternatively, even with long (o) in wall - hall- call - tall. e. $/ \mathrm{o} /$ and /ou/ are mixed by FL beginners as $<\mathrm{o}$, for ,ow $>$ as in /go/ for /gəu/ or long $<0>$ law- draw- in addition to the spelling areas of cow- how $\mathrm{f}$. The schwa vowel areas do not exist in Arabic. It is an area of common mistake as inearn- burn - word - bird /b ə: d/ to be berid. or particular being pronounced /particular/ for /pə'tikjələ/, apply, carrot - correct - g. /ei/ and /ou/ as diphthongs are usually pronounced short as in hope which is pronounced /hop/ for /həup/ .( lik for like /laik/). or (cry, krei for / krai/ As an area of confusion between sounds and spellings. In fact, all vowels cause problems for FL learners. Especially when they are compared with Arabic ones. Thus, all students produce incorrect sounds. The fact that the tables for results' reflect their lower performance. From the first test's results, it is found that the two groups are similar. There is no statistical differences between both of them when they applied the same practice, which reflects their improvement in the posttest. This shows that Most of EFL learners of English have problems in the segmental vowel phonemes areas. In particular, the areas that is different from Arabic.

\subsection{Analysis of Consonants}

The results of the second test shows that all students do not have problems in the areas which exist in their mother -tongue as $<\mathrm{b}, \mathrm{d}, \mathrm{t}, \mathrm{g}, \mathrm{k}, \mathrm{f}, \mathrm{s}, \mathrm{z}, \mathrm{z}, \mathrm{h}, \mathrm{m}, \mathrm{n} \mathrm{p}, \mathrm{l}, \mathrm{w}, \mathrm{j}>$. Most of them pronounce this sounds $<\mathrm{p}, \mathrm{v}, \mathrm{d}, \theta, \int$, $d_{3}, \eta>$ incorrect. That is to say, Arab FL learners commit common mistakes in the areas of (consonants and clusters). They fail to grasp acceptable pronunciation, especially sounds that do not exist in Arabic. On the other 
hand, they tend to replace them by Arabic sounds that do not exist in English (contrastive areas). From students' test and interview questions, the researcher reaches to the following points: a./p/causes problems to EFL learners of English and many graduate teachers. / $\mathrm{p} /$ is replaced by the nearest sound, which is similar to Arabic $/ \mathrm{b} /$ as /big/ for pig /board/ for port. /b/ is found in Arabic but /p/ doesn't b./v/ also confused with the sound /f/ as /ferry/ for very. That is refers to the foreign sound $/ \mathrm{v} /$ which does not exist in Arabic. b./t/ sometimes confused with Arabic $<b>$ as in /tall. That is to say, EFL learners pronounce some words according to their mother tongue. Moreover, students mispronounced these areas. c. $/ \mathrm{d} b /$ and $/ \mathrm{t} / /$ do not exist in Arabic. So, learners tend to substitute $/ \mathrm{t} / /$ for $/ \mathrm{d} z /$ and produce meaningless word as agent $/$ eit $\int \mathrm{nt} /$ for $/$ eidznt/. d./ $/ \theta /$ and $/ ð /$ are often confuse in addition to their spelling areas . Students change the sound $/ \theta /$ to be $/ \mathrm{s} /$ as $/$ sree/ for $/ \theta$ ri:/ and they also use $/ \mathrm{z} /$ for $/ ð /$ as /zis/ then produce meaningless words. /D/ doesn't occur in Arabic. It is replaced by /nk/ ang /ng/ as/ $/$ ing/ for $/ \mathrm{sin} /$. As a result, FL learners tend to substitute some of Arabic consonants by others, and transfer these habits of their own sound into English. f. From the table for second test's results, it is clear that both groups are the same in number. The statistical difference occurs, when the experimental group is treated with especial listening practice (using a laptop) through drills intensively before having the posttest (see Appendix). g. After comparing their posttest results, the experimental group's performance becomes better than the control one. $\mathrm{h}$. It is generally more difficult for non-native speakers to see the differences between writing and producing short vowel sounds than long vowel sounds.

\subsection{Analysis of Consonant Clusters}

From the learners test: The researcher reached to the point that: The problems of clusters, which cause difficulty for learners is length. EFL learners pronounce words according to their spelling. They lengthening consonants when no length is needed. From the students test and interview questions: a. Initial clusters cause problems for beginners as/pl/, /st/, /sk/, /sp/, /sn/ as please, stop, school clean ,spring and snake . Most of students insert the phoneme /i/ within clusters as /istop/ or /ispoon/, /pilies/, / kilin/, /ispik/, /isneak/ or istreet, ispring, iscratch and produce incorrect words to assist pronunciation . b. Medial clusters $/ \mathrm{nst} /$ constant, /str/ administration //rld/ world etc. Most of them insert /i/ and say non - English words as compilite, conistruct. c. Arab learners tend to insert short vowels in final clusters such as /worlid/, /monthiz or /nekist/etc. d. FL learners add/i/ with syllabic consonants $(1, \mathrm{~m}, \mathrm{n})$ as in: /litil/ for lillie, /d^znit/ for doesn't/didint/ for didn't. That is to say, segmental clusters initially; medially and finally do not occur in Arabic at all. e. When FL students are reading conventionally spelled English. They come across words' containing (double letters, which they automatically interpret as phonemic length, for example connect, correct and collect. They lengthen these areas as well as what they used to do in their mother tongue.

\subsection{Analysis of Conversations}

This copy Right conversations test, clarify many errors of speech and the speed or methods of communication.

\section{Summary of Resulte and Recommendations}

The data was collected through the test, which was presented in statistical analysis. Those results are the outcome of the data analysis. They represent many evidence for the research hypotheses.

\subsection{Results in the Light of Hypotheses}

The results of this study summarize the major findings of the research:

The first hypothesis is tested by this research is that, most of EFL learners have communication problems T-Test statistical measurement is used to compare their performance. The findings based on observations collected from classrooms', real environment are the real evidence in comparison with the test'results. That the hypotheses come to truthfulness. The first hypothesis tested by this research is that, most of Arabic learners of English have segmental problems in the areas of segmental sounds (vowels and diphthongs). By comparing mean scores and standard deviation as well as T-values and $\mathrm{P}$ - values for the two groups' first test, it is found that, there are significant differences between English and Arabic sound systems which cause these problems. Thus, the findings of this study indicates that this hypothesis is true.

For the second -Test's results in the areas of consonant and clusters. For the purpose of the requirement of the study, in order to find out if there is any individual differences between both groups. This makes it sure that the statistical difference occurs in favor of the experimental group's treatment. On the other hand, the control group assign lower percentage. This result explains that, Arabic .FL learners commit common mistakes in the areas of (consonants and clusters). They fail to grasp acceptable pronunciation. These problems occur according to the English consonants that do not exist in Arabic. On the other, hand the effect of learners'translations

The finding of this study indicates that, it is due to their lack of motivation. In addition to their needs to new 
technological methods and more practice. By comparing the learners low achievement in English communications in the whole test, it shows their lack of( good teaching and enough practice ) From a general point of view, all the research results are in favor of the research hypothesis. That all the above mentioned hypotheses are proved to be correct.

\subsection{Challenges}

As mentioned above, the Arabic language is from the Semitic language family. Therefore, the body of L1 and L2 are different. There is a large potential for errors of interference when the Arabic students use the English language. Its alphabet, grammar, vocabulary, etc., are very different.

For example, the Arabic language has the nouns and adjectives and the work of those word families are similar to that of English, but the placement of them in the sentence differs. We use an adjective before the Noun to qualify, but they use first noun and adjective later. For Example, Arabic learners use She teacher and her happy or Book Selma instead of Selma's book. The pronouns also cause some problems for students when using them in English for example (herself- itself -himself or themselves etc). They try to use them regarding their translation to Arabic. On the other hand, learners produce "She is angry from me" instead of with. Moreover, the (ed) past tense (liked - picked or failed -opened) pronounced the same. At the primary levels, in the alphabetic method, Arab students are taught the names of the English letters. The letters of a language's writing system, confuse with its sounds for example, (c "see" is an alphabetical letter which is pronounced as $/ \mathrm{s} /$ or $/ \mathrm{k} /$ ), and when FL learners come to put these letters together to form a word according to word's spelling letters. Another chief source of difficulty is the areas where English differs from their native language (contrastive areas). In the light of these differences, The main reason for teaching sounds is to help the students practice using (IPA) examples such as long front vowel /I:/ spelling areas: The other biggest pronunciation challenge for the Arabic speakers is to differentiate the sounds $/ \mathrm{p} /$ and $/ \mathrm{b} /$. They use the sound $/ \mathrm{b} /$ whenever they produce $/ \mathrm{p} /$ sound. They cannot differentiate the $/ \mathrm{f} /$ and $/ \mathrm{v} /$. They find it difficult to pronounce the letters (the) in think and this has two different pronunciation. In the areas of teaching consonant sounds: example $/ \mathrm{f} /$ although there is no problem of pronouncing the sound because it is found in Arabic but the problems occur from the spelling areas of English the sound when they pronounce the words according to their spellings. $<$ sh $>$ spellings $<$ sh $>$ she $/ \int \mathrm{i}: /<\mathrm{ti}>$ nation /neifn/ < ci $>$ magician /mə’ djifən/ <ch $>$ machine /mə’fi:n/ <s $>$ sugar / Jugə/ <sch $>$ schwa / wwa:/ < e $>$ ocean

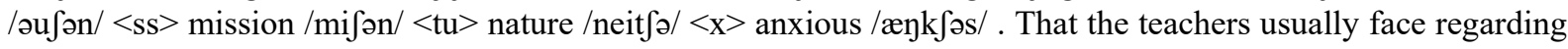
confusions of spellings or mother- tongue interference.(such) of schwa is also found in the school schedule. In addition to the alphabetical differences and Capitalizations. For example in English capital (A) is used for Ali and Ahmed while these names have different initial letters in Arabic. There is no one -to- one correspondence between sounds and letters. That is to say, the same letter cannot represent each different sound. There are also words, which are spelt differently but sound the same. Conversely, there are words which are spelled the same but they sound differently. However, the reading and spelling skills are not closely related to each other. That is because the English alphabet has fewer letters to represent speech sounds in a way that is consistent, comparable across different languages, and especially Arabic. It means that other problems appear between English sounds and spellings or the way English is written and spoken. Then sounds must be distinguished from letters. On the other hand, the vowel phonemes of English and Arabic languages are different. The main problems appear during the contrastive study of phonemic vowel sounds between English and Arabic. In particular, the areas where English has differed than learners' mother - tongue. Another part of pronunciation problems is that although teachers are the best models for their students in ELT, most of them do not consider pronunciation as a relevant part of their education. In addition to that, the effect of graduate teachers' role in the teaching/ learning process of ELT.

\subsection{Recommendations}

1. The teacher is the backbone of the learning process. That the teachers' role affects the teaching /learning process to a high degree. Therefore, effective (happy) learning is very important. These types of difficulties need motivation and creativity of natural environments 2. Listening to recorded native speakers' discourse. 3. English intensive drills in the areas of vowels, diphthongs, consonants, clusters, stress and intonation lead learners toward correct pronunciation. 4. Intensive sound discrimination drills. 5. The computer improves teaching pronunciation and arises students' motivation towards learning English. 6. Continuous training, Seminars in addition to demonstration lessons help graduate teachers to be qualified. 7 . The creativity of an effective learning environment leads to students' motivation. To let the responsibilities shared by the members of the groups is another way of classroom's encouragement. Interpersonal communication is required for oral communication in a social context. To select a cultural meaningful text and help learners to dramatize the dialogue; after knowing its words and meanings is a point of higher participation. 8. The challenge regarding audio-visual aids and a 
language lab. On the other hand, the teachers' office hours and their free time, can offer suggestions. In addition to their experience in teaching English is needed to tackle these problems. Another challenge lies in the courses' specifications in the curricula that are in need of changes to meet the learners' requirements. Challenge of students' absenteeism, deprived or prohibited also lead to a lower standard and weakness.

\section{References}

Brisk, M., E. (2010). Learning English as a second language. In M. Shatz, \& L., C. Wilkinson (Eds.), the education of English language learners (pp. 152-173). New York: The Guilford Press.

Brown, H. D. (2000). Principles of language teaching and learning. 4thedition. White Plains, NY: Longman.

Brown, H. D. (2001). Teaching by Principles: An Interactive Approach to Language Pedagogy (second Ed.). New York: Addison Wesley Longman, Inc.

Clark, E. (2003). First language Acquisition. Cambridge: Cambridge University Press.

Clark, J. (2001). An Introduction to Phonetics and Phonology. Oxford: Blackwell.

Carston, R. (2004). Thought and utterances: The study of explicit communication. Oxford: Blachwell

Cook, V. (2008). Second Language Learning and Language Teaching. London.

Copyright 2005 Shahriar Bourbour, All rights reserved.

Ehsan, M. A (2011). Phonological Problems Affecting the Teaching/Learning Process of ELT: A Case Study Of Sudanese Secondary School Students. Retrieved from https://search.mandumah.com/Record/832106

Ehsan, M. A., \& V. S. V. Laxmi, R. (2017). A Handbook on Introduction to Phonetics \& Phonology For Arabic Students, Notion Press, Chennai.

Ehsan, M. A., \& Ramana, V. L. (2016). Challenges of Teaching English to Arabic Students, 4(11), 221-227.

Katamba, F. (2005). English Words: Structure, History, Usage. London: Routledge.

Lujan, A. B. (2006). The American Accent Guide 2 Lake City: Lingual Arts. Yatll.

Yates, J. (2004). Pronounce It Perfectly In English. Barron's Educational Series, Inc.

\section{Appendix 1}

Language is a system of Arbitrary vocal symbols which permit all people in a given culture, or other people who have learned the system of that culture to communicate or to interact. It is a system of communication by sounds, operating through the organs of speech and hearing amount members of a given community; using vocal symbols possessing arbitrary conventional meanings. Segmental features in English consist of const and vowels

Vowels: Put the vowels between the consonants to make and say words:

\begin{tabular}{|c|c|c|c|c|c|}
\hline 1.(a) & $c_{-} t$ & b_ck & $\mathrm{b} \quad \mathrm{d}$ & $\mathrm{d} \_\mathrm{d}$ & $\mathrm{m}_{-} \mathrm{tch}$ \\
\hline 2.(e) & $\mathrm{m}_{-} \mathrm{t}$ & $\mathrm{w} \_\mathrm{t}$ & $\mathrm{m} \_\mathrm{n}$ & $r_{-} d$ & $b_{-} d$ \\
\hline 3.(i) & $\mathrm{b}$ & $\mathrm{p} \_\mathrm{n}$ & $\mathrm{t}$ & $\mathrm{h} \_\mathrm{t}$ & $\mathrm{h}_{-} \mathrm{m}$ \\
\hline 4.(o) & $1 \_\mathrm{t}$ & $1 \_$ck & $\mathrm{sh} \_\mathrm{ck}$ & $\mathrm{n} \_\mathrm{t}$ & fr_ $n t$ \\
\hline 5.(ee) & $\mathrm{m} \_\mathrm{t}$ & $\mathrm{f} \_\mathrm{d}$ & b_ n & f_l & $\mathrm{f} \_\mathrm{t}$ \\
\hline 6.(ea) & $\mathrm{r}$ & $\mathrm{t} \quad \mathrm{m}$ & $\mathrm{m} \_\mathrm{n}$ & $b_{-} \mathrm{n}$ & $r_{-} d$ \\
\hline 7.(ie) & $\mathrm{P} \_$_ee & $\mathrm{n} \_$ce & $\mathrm{Pr} \_s t$ & $\mathrm{~s} \_\mathrm{ge}$ & $f_{-} l d$ \\
\hline 8.(oo) & $\mathrm{g} \_\mathrm{d}$ & $\mathrm{m}_{-} \mathrm{n}$ & $\mathrm{w} \_\mathrm{d}$ & $1_{-} \mathrm{k}$ & c__ 1 \\
\hline 9.(ou) & c_ld & sh_ld & o__ gh & w_ld & b_ght \\
\hline
\end{tabular}

The teacher tests the learner's receptive ability by giving her a chance $t$ read these words:

Consonants

a. pin, bin, pet, bet, pack, back

b. rapid, rabid, pear, bear

c. safe, save, half, have, fan, van 
d. judge, church, reach, bridge

e. chin, she's, cheese, chose, choose

f. shoot, suit, sew, show, shine sign

g. shame, same, self, shelf, place, plays

h. sue, zoo, rice, rise, wise, nice

i. ring, swing, wing, sing, stung, tongue

j. thing, sing, swim, thin, then, tin

k. think, sing, Zink, zin

Consonant clusters

1. Keep practicing.

2. Grab Brains hand

3. That little pup belongs to her.

4. It's not too much.

5. Dad didn't tell me.

6. Don't do that. Don't be stupid.

7. The program was recorded.

8. That's another world.

9. Spring is a season.

Janice, did you see the soldier?

\begin{tabular}{llllll}
\hline$/ \mathrm{t} / /$ & $/ \mathrm{J} /$ & $/ \mathrm{t} /$ & $/ \mathrm{J} /$ & $/ \mathrm{t} /$ & $/ \mathrm{J} /$ \\
\hline Cheat & Sheet & watches & washes & witch & wish \\
Cheap & Sheep & catching & cashing & ditch & dish \\
Chapter & Shaper & marches & marshes & march & marsh \\
\hline
\end{tabular}

Appendix 2

Consonants' contrastive areas of sounds:

\begin{tabular}{|c|c|c|}
\hline English only & Arabic only & English and Arabic \\
\hline$/ \mathrm{p} /$ & ض (d) & $/ \mathrm{b} /$ \\
\hline$/ \mathrm{g} /$ & ق (q) & $/ \mathrm{t} /$ \\
\hline$/ \mathrm{t} / \mathrm{t}$ & (؟) & $/ \mathrm{d} /$ \\
\hline$/ d z /$ & (t) & $/ \mathrm{k} /$ \\
\hline /3/ & ص (ş) & $/ \mathrm{f} /$ \\
\hline$/ \mathrm{v} /$ & (h) $\tau$ & /ð/ \\
\hline$/ \mathrm{y} /$ & ) & $/ \theta /$ \\
\hline \multirow[t]{7}{*}{$\mid 3 /$} & $(\mathrm{x}) \dot{\tau}$ & $/ \mathrm{s} /$ \\
\hline & (ð) & $|\mathrm{z}|$ \\
\hline & همرة (?) & $/ \mathrm{h} /$ \\
\hline & ل & $/ \mathrm{m} /$ \\
\hline & & $/ \mathrm{n} /$ \\
\hline & & $/ 1 /$ \\
\hline & & $/ \mathrm{r} /$ \\
\hline
\end{tabular}




\section{/w/ \\ /j/ \\ $/ \mathrm{y} /$}

Appendix 3

\begin{tabular}{ccc}
\hline Arabic & I.P.A & English \\
\hline$<>>$ & $/ \mathrm{b} /$ & $<\mathrm{b}>$ \\
$<>$ & $/ \mathrm{h} /$ & $<\mathrm{h}>$ \\
$<\dot{\mathrm{r}}>$ & $/ \mathrm{x} /$ & $<->$ \\
$<\mathrm{G}>$ & $/ \mathrm{q} /$ & $<\mathrm{q}>$ \\
$<\square$ & $/ \mathrm{k} /$ & $<\mathrm{k}><\mathrm{c}>$ \\
$<>$ & $/ \mathrm{m} /$ & $<\mathrm{m}>$ \\
$<->$ & $/ \mathrm{\eta} /$ & $<\mathrm{ing}>$ \\
$<->$ & $/ \mathrm{v} /$ & $<\mathrm{v}>$ \\
$<->$ & $/ \mathrm{t} /$ & $<\mathrm{ch}>$ \\
$<->$ & $/ ? /$ & $<->$ \\
$<j>$ & $/ \mathrm{z} /$ & $<\mathrm{z}>$ \\
$<->$ & $/ \mathrm{p} /$ & $<\mathrm{p}>$ \\
$<->$ & $/ \mathrm{j} /$ & $<\mathrm{y}>$ \\
$<->$ & $/ \mathrm{g} /$ & $<\mathrm{g}>$ \\
\hline
\end{tabular}

\section{Copyrights}

Copyright for this article is retained by the author(s), with first publication rights granted to the journal.

This is an open-access article distributed under the terms and conditions of the Creative Commons Attribution license (http://creativecommons.org/licenses/by/4.0/). 